\title{
ENTREVISTA COM BÁRBARA WEINSTEIN
}

\author{
Interview with Bárbara Weinstein
}

Luciana da Cruz Brito*

Luciano Everton Costa Teles**

\section{APRESENTAÇÃO}

Bárbara Weinstein atua como professora na New York University, nos Estados Unidos da América. Esteve no Brasil recentemente, em especial no Amazonas, participando do IV Seminário Internacional Mundos do Trabalho / VIII Jornada Nacional de História do Trabalho, evento acadêmico realizado em Manaus, na Universidade Federal do Amazonas em novembro de 2016, que reuniu uma quantidade expressiva de pesquisadores nacionais e internacionais envolvidos com a História do Trabalho.

A Amazônia não é nenhuma novidade para Bárbara Weinstein, que já visitou a região em outros momentos, particularmente no seu processo de doutoramento, quando, então, necessitou realizar pesquisas em $\operatorname{arquivos}^{1}$ (documentos cartoriais, jornais, dentre outros) para fundamentar empiricamente a sua reflexão acerca da expansão da economia gomífera na região. Após a defesa de sua tese e a publicação de seu livro em inglês $(1983)^{2}$, a sua obra foi traduzida para o português em $1993^{3}$, tornando-se fundamental para a compreensão da exploração da borracha na região Amazônica.

Estudou também sobre a formação do operariado paulista entre os anos de 1920 e $1964^{4}$. Atualmente Bárbara Weinstein desenvolve análises sobre as relações raciais e a identidade regional no Brasil, articulando-os com o discurso nacionalista sobre a modernidade e a democracia racial, mantendo, dessa forma, fortes ligações acadêmicas com estudantes e pesquisadores do país. Foi na sua marcante presença no IV Seminário Internacional Mundos do

\footnotetext{
* Professora do colegiado de História na Universidade Federal do Recôncavo da Bahia, UFRB. É pós-doutora em História pela Universidade da Cidade de Nova York (CUNY) e doutora em História pela Universidade de São Paulo. E-mail: lucianabrito@ufrb.edu.br

** Doutor em História pela Universidade Federal do Rio Grande do Sul. Mestre em História Social pela Universidade Federal do Amazonas. Professor Assistente da Universidade do Estado do Amazonas. E-mail: lucianoeverton777@hotmail.com

${ }^{1}$ Biblioteca Pública do Pará, Arquivo Público do Pará, Museu Emílio Goeldi, dentre outros.

2 WEINSTEIN, Bárbara. The Amazon Rubber Boom, 1850-1920. Stanford University Press: Stanford, 1983.

${ }^{3}$ WEINSTEIN, Bárbara. A borracha na Amazônia: expansão e decadência (1850-1920). São Paulo: HUCITECEDUSP, 1993.

${ }^{4}$ WEINSTEIN, Barbara. (RE)Formação da Classe Trabalhadora no Brasil (1920- 1964). São Paulo: Cortez: CDAPH-IPHAN - Universidade São Francisco, 2000.
} 
Trabalho que lançamos o convite sobre a possibilidade de uma entrevista, que ela gentilmente aceitou.

1. Quando e como surgiu seu interesse pela história do Brasil, em especial da Amazônia?

B.W.: Meu interesse pela história do Brasil começou na graduação com o tema da escravidão comparada, um assunto que estava muito na moda naquela época (início dos anos 70). Mas quando entrei no programa de pós-graduação, logo depois de ter lido a obra-prima de E. P. Thompson, The Making of the English Working Class, minha proposta era pesquisar a história da classe trabalhadora na Argentina. Foi a minha orientadora, Emília Viotti da Costa, que me levou pra o campo da história do Brasil. Quanto à Amazônia, como relatei num recente artigo publicado na Revista Brasileira de História, optei pela história do ciclo da borracha, em primeiro lugar, porque eu queria fazer pesquisa sobre um tema que estava sendo pouco investigado pelos historiadores no Brasil. Mas não foi só isso. Naquele momento, havia uma linha de crítica neoMarxista da teoria de dependência, com sua tendência determinista que situava os países do Terceiro Mundo ou da "periferia" na posição de vítima passiva, e de certa forma, marginalizava a própria história desta suposta "periferia". Para quem estava pesquisando a história aqui no Brasil, onde a história do Brasil era valorizada "automaticamente", isto talvez não fosse uma grande preocupação. Mas para mim, fazendo carreira na academia norte-americana, o perigo da história da "periferia" virar história periférica era, sim, uma grande preocupação. Então, minha ideia foi trabalhar com a história da Amazônia - uma região que quase todo mundo considerava "a periferia da periferia" - e mostrar que mesmo na Amazônia a abordagem "dependentista" não era adequada para entender nem o percurso nem as repercussões do ciclo da borracha.

2. O projeto de pesquisa elaborado sobre a Amazônia do período da borracha se deu nos anos 70 e resultou num livro que se tornou academicamente obrigatório para aqueles que buscam entender a estrutura e a dinâmica da economia de exportação do látex. Quando da elaboração do projeto, e considerando as relações E.U.A./Brasil, quais foram os referenciais teóricos adotados e de que forma foram operacionalizados na pesquisa?

B.W.: Talvez a referência teórica de maior impacto no meu livro sobre a Amazônia e o ciclo da borracha tenha sido um pequeno artigo do teórico argentino, Ernesto Laclau, "Feudalism and Capitalism in Latin America", publicado na New Left Review, no qual ele fez uma crítica profunda da escola dependentista, especialmente do Andre Gunder Frank. O Laclau, diferente do Frank, insistiu que as relações pré-capitalistas não implicam a ausência do mercado e, pela mesma lógica, a penetração de relações comerciais não implicam que uma economia seja "capitalista". Laclau ressaltava a questão das relações de produção (em vez de circulação), e isto me permitiu pensar no ciclo da borracha como um fenômeno que era, de um lado, altamente comprometido com novas tendências na economia capitalista global, mas ainda caraterizado por um sistema de produção que seria difícil chamar de capitalista. Outra importante influência 
para o argumento do meu livro foi um artigo do historiador norte-americano Arnold Bauer, um "mexicanista", sobre "Rural Workers in Spanish America: Problems of Peonage and Rural Oppression". Ele mostrou como a historiografia do mundo agrário aceitou certa interpretação do papel das dívidas nas relações de trabalho que tratavam deles exclusivamente como instrumentos de coerção, sem reconhecer as oportunidades para resistência, mobilidade e negociação da parte do "peão". Isto foi fundamental para o processo de repensar a relação entre o aviador e o seringueiro, que eu continuava achando uma relação de exploração, mas não algo análogo à escravidão. E uma terceira influência foi um estimulante artigo do antropólogo brasileiro João Pacheco Filho, "O caboclo e o brabo: Notas sobre duas modalidades de forçade-trabalho na expansão da fronteira amazônica no século XIX", que ressaltou as variações dependendo da época e do contexto cultural - nas relações de produção e troca no ciclo da borracha. Como se pode ver desta lista composta de um argentino, um norte-americano e um brasileiro, a circulação de ideias no mundo acadêmico já transbordava as fronteiras nacionais.

\section{Como foi sua experiência de pesquisa na Amazônia?}

B.W.: De certa forma, minha experiência de pesquisa na Amazônia - e especificamente em Belém do Pará - foi ótima. Além do lugar óbvio - a Biblioteca e Arquivo Público do Pará fiz pesquisa em vários cartórios, no acervo da Associação Comercial do Pará, no arquivo do ITERPA (Instituto de Terras do Pará) e no Museu Goeldi. Em cada um destes lugares, os funcionários foram super atenciosos, mesmo nos cartórios onde a presença de uma pesquisadora norte-americana era algo inteiramente estranho. Ao mesmo tempo, foi triste ver a absoluta falta de recursos para a preservação e organização da documentação. No BAPP (como o arquivo do Estado foi conhecido nos anos setenta), quem fazia pesquisa sobre a época colonial ainda encontrava um acervo relativamente completo e bem organizado, mas do século XIX para frente era uma tristeza. Hoje as condições para fazer pesquisas sobre a época pós-colonial certamente são melhores, mas continuam sendo um desafio.

4. Você também estudou a formação do operariado paulista entre 1920 e 1964. Escolheu esse tema para ampliar sua compreensão acerca da história do Brasil? Ou existiram outras razões para tal empreitada?

B.W.: Havia uma série de motivos para a escolha do tema do meu segundo livro. Eu já contava com a história da classe operária e da industrialização entre minhas áreas de interesse, e até tinha pensado em fazer a tese de doutorado sobre "a formação da classe operária paulista". Depois ficou claro que eu precisava identificar um assunto um pouco menos abrangente e, justamente quando eu estava completando o livro sobre a Amazônia, tive uma conversa com Alexander Marchant, um brazilianist daquela primeira geração. Foi ele que me falou da existência do SENAI e do SESI, e, então, eu comecei a pensar neles como a porta de entrada para um estudo sobre empresários e operários em São Paulo. E mais uma coisa: como uma novayorkina nata, achei que - ao final das contas - a vida em São Paulo ia ser um pouco mais fácil para mim. Adorei o tempo que passei em Belém e as amizades que fiz naquela cidade, mas 
sempre ia me sentir "uma gringa" lá, enquanto em São Paulo minha identidade como estrangeira não era tão evidente.

5. Em seu livro, você afirma que a Identidade paulista foi construída sob pilares raciais e em contraposição com a região nordeste. Como essa identidade paulista se encaixa (ou não) com o discurso da identidade nacional brasileira?

B.W.: Acho que faz mais sentido falar de discursos (plural, e não singular) de identidade nacional. Todo discurso de identidade nacional tem suas raízes em um lugar específico (Rio, Bahia, o Sertão) que, por uma série de razões, num certo momento se torna plausível como identidade brasileira (e não apenas carioca ou baiana). A identidade paulista, porém, estava (e talvez ainda esteja) construída de uma maneira que dificulta a sua transformação para uma identidade mais abrangente. Ao mesmo tempo, e de acordo com o trabalho da Tânia de Luca, vejo a identidade paulista como um discurso de identidade nacional, porém um que pensa em São Paulo como a nação imaginada. Todo historiador, do meu ponto de vista, tem que lidar com os discursos de identidade nacional como ficções com verdadeiras implicações políticas e culturais. Uma vez um aluno meu, um norte-americano, que estava cursando um semestre na USP, escreveu-me para dizer que tudo ia bem, mas que ele estava louco para fugir de São Paulo e ir à Bahia para conhecer "o Brasil de verdade", uma declaração que remete a uma gama de estereótipos. Claro que não aceito a ideia de São Paulo como o Brasil que deu certo, mas São Paulo também é "o Brasil de verdade".

6. Sobre a diversidade do discurso de identidade nacional. Como essa noção dialoga com os estudos de transnacionalidade? Qual a contribuição e limites dos estudos comparativos nesse caso?

B.W.: Há duas versões do "transnacional" como abordagem histórica. Uma constrói um problema explicitamente de um modo que vai além dos limites de uma única nação, mas ainda se preocupa com a constituição das identidades nacionais. A outra privilegia o espaço do transnacional como objeto de pesquisa. A questão regional, para mim, liga-se mais à primeira versão; é uma outra maneira de questionar a primazia da nação, mas o regional não faz sentido sem o nacional.

Falando da questão da comparação, em geral acho que temos que tomar muito cuidado. No meu trabalho sobre identidade regional, o que me interessava foi a maneira na qual os paulistas utilizavam a comparação, especialmente o contraste entre a sua região e o nordeste. Então o discurso comparativo foi um objeto de pesquisa e não um modo de pesquisar. Porém, fiz algumas rápidas comparações com o norte da Itália, a Antioquia, na Colômbia, e a região de Santa Cruz, na Bolívia - outros casos de regionalismo caraterizados por um discurso de superioridade e de brancura. Isto foi para mostrar que o caso de São Paulo, em termos gerais, não é singular. Mas eu não pretendia fazer uma comparação mais aprofundada. 
7. Podemos afirmar que a crescente onda conservadora no Brasil, que tem em São Paulo um dos seus locais referenciais, o discurso de ódio contra nordestinos, por exemplo, é uma continuidade do discurso de excepcionalidade paulista que você verificou na Revolução Constitucionalista e no Centenário da fundação da cidade?

B.W.: Como indico no epílogo do Color of Modernity, devemos tomar muito cuidado com a questão da continuidade. Certamente a memória da "Revolução Constitucionalista" e os textos e monumentos que sobraram do IV Centenário são elementos que contribuem para construir uma identidade regional de superioridade/excepcionalismo, junto com a sua contrapartida, o desdém para com o nordeste e os nordestinos. É sempre uma latência, digamos, que pode ser mobilizada num momento pontual. Ao mesmo tempo, é preciso reconhecer que esta ressuscitação do discurso de excepcionalismo é a consequência de um projeto político que reflete muito mais o contexto atual, e os interesses atuais, e muito menos os "resquícios" do passado.

8. Falando em estudos comparativos e transnacionais, você arriscaria afirmar que existem similaridades entre o discurso conservador e racializado da "superioridade paulista" e aquele discurso conservador e supremacista branco que elegeu Donald Trump? Como explicar essa criação do outro não-branco (nacional ou estrangeiro) nas Américas, mais especificamente no Brasil e nos US?

B.W.: Não há a menor dúvida que a derrota da Hillary e o impeachment da Dilma (junto com a eleição do Duterte nas Filipinas, Erdogan na Turquia, o sucesso da Brexit, a derrota do Plano de Paz na Colômbia e vários outros desdobramentos políticos no mundo atual) fazem parte de uma forte tendência global que está revigorando uma vertente da direita caracterizada por um "nativismo" branco/masculino/heterossexual. Isto obviamente não quer dizer que nenhuma mulher ou pessoa de cor possa apoiar o Trump ou LePen ou Uribe, mas sim que os valores culturais embutidos nestes movimentos políticos privilegiam a brancura, a masculinidade, etc. Cada contexto nacional tem suas especificidades - no Brasil a questão da corrupção está ocupando um lugar de destaque enquanto nos States parece que muita gente admira as várias manobras financeiras do Trump. Mas em todos os exemplos indicados, o pano de fundo é o ressentimento de um certo segmento da população que identifica o problema como algo originado das camadas mais pobres, mais escuras, dos imigrantes legais ou ilegais, em vez de responsabilizar o "1 por cento" que está acumulando uma porção cada vez maior e mais espantosa da riqueza mundial. Só para dar uma ideia da desigualdade no meu país, os bens dos 400 indivíduos que compõem a lista das pessoas mais ricas do país, segundo a revista Forbes, valem mais do que os bens de toda a população afrodescendente do país e mais uma terceira parte da população latina, que dá um total de 21 milhões de lares. Tenho a impressão que muita gente - inclusive gente relativamente humilde - não quer contemplar a possibilidade desta situação ser uma profunda injustiça. Quando você começa a questionar se o rico merece ou não o dinheiro que tem, onde é que vai terminar? Será que os brancos são mais ricos simplesmente por causa do racismo? Os homens são dominantes apenas por causa do sexismo? Será que não há uma verdadeira justificativa para certas pessoas morar em países pobres e outros em países relativamente ricos? Muita gente tem pavor de entrar neste tipo de raciocínio, que tem o 
potencial de desmanchar toda a estrutura do seu mundo. É muito mais fácil responsabilizar a pessoa de (mais) cor, o imigrante, a mãe solteira, etc. E é uma visão de mundo reforçada pelas várias tendências fundamentalistas religiosas.

Há mais uma consideração nos casos específicos dos EUA e do Brasil. Nas últimas eleições norte-americanas, os eleitores afrodescendentes e latinos votaram maciçamente em favor do Partido Democrático. Entretanto no Brasil, o Nordeste virou o baluarte do Partido dos Trabalhadores. Então, para explicar e deslegitimar o sucesso do Obama ou do Lula e da Dilma nas urnas, uma estratégia era desqualificar os segmentos da população que votaram neles. Nos Estado Unidos isto acontecia de uma maneira concreta - novas exigências para o acesso ao voto eliminaram milhões de pessoas dos registros de eleitores. Mas igualmente importante é a tentativa, quer no Brasil quer nos States, de retratar certos segmentos da população como incapazes de fazerem avançar os "verdadeiros interesses" do país e estarem voltados unicamente à expansão dos programas de bem-estar. Uma placa que apareceu num comício contra a Dilma em São Paulo no ano passado, apresentou este sentimento de uma maneira bem concisa: "Mais Coxinha, Menos Acarajé". Pronto.

9. Para finalizar, considerando a historiografia norte-americana, que tendências são possíveis verificar na atualidade acerca dos estudos históricos voltados para a América Latina e o Brasil?

B.W.: No último congresso da American Historical Association (nossa Anpuh) participei em três mesas sobre a questão regional na América Latina. Então acho que este é um tema que continua sendo de muito interesse na área. Há uma nova onda de pesquisas sobre a história econômica, mas uma que questiona categorias e conceitos e que está preocupada em ir além do positivismo e empiricismo da historiografia anterior. Influenciada pela teoria póscolonial, esta nova tendência historiográfica quer se distanciar de certas teologias ligadas às noções de progresso e atraso. Vários livros recentes tratam de questões de consumo, da cultura de jovens e da contracultura (especialmente nos anos sessenta), da cultura popular e da relação entre sistemas de direito e vida cotidiana. Entre quem trabalha com a história do Brasil, a escravidão e a emancipação continuam sendo temas centrais, com atenção (como se encontram entre os historiadores aqui no Brasil) aos muitos fatores que complicam a divisão entre trabalho escravo e trabalho supostamente "livre". Há também um interesse renovado na história indígena, e agora não apenas na época colonial. 